\title{
A NEW PROGRAMME OF SEX EDUCATION AND COUNSELLING FOR SPINAL CORD INJURED ADULTS AND HEALTH CARE PROFESSIONALS
}

\author{
By Theodore M. Cole, M.D., Richard Chilgren, M.D., \\ and Pearl Rosenberg, Ph.D. \\ University of Minnesota Medical School
}

\section{THE PROBLEM}

ThRoUGHOUT the world today men and women with traumatic paraplegia and quadriplegia are making increased demands on the health care system to do more than simply manage them through their immediate post injury period. They require workable solutions to the totality of psycho-social problems inherent in a continued state of disability. Yet, Professor Timothy J. Nugent, past President of the National Paraplegia Foundation (I97I), pointed out that many of the assumptions of the past and some of the advice given in clinics today actually result in more psychological, emotional and social trauma than the physical situation justifies. He believes that the social-psychologic trauma is not simply experienced by the individual, but that it has been imposed on him and can become fixed after many years.

In the past, traditional medical and surgical care for paraplegia has tended to focus on treating the patient for such common medical complications of spinal cord injury as joint contractures and decubitus ulcers. Rehabilitation therapy has concentrated on fostering independence in self care. Vocational rehabilitation has trained the patient for returning to his job or has provided him with a new, marketable skill. Within the larger framework of acute, restorative and rehabilitative treatment of the spinal cord injured lies the relatively ignored area of diagnosis and treatment of sexual function after spinal cord injury.

Those with spinal cord injury protest that like able-bodied people, they also are entitled to a satisfactory sex life, a respectable self image and the expectation of being treated like other people who have a need for emotional, sexual expression. They are becoming less content to lead lives affected by the myths commonly believed by many medical personnel and others in society. Some of these myths suggest that handicapped people have no sexual needs or desires; others imply that people with physical disability have excessive or perverted sexual needs. Unfortunately, when patients are treated by health care professionals who hold these beliefs, the tenor of treatment may be such that it predisposes the patient to act and live according to the beliefs of the treater. In some cases, the physician's personal anxieties regarding sexuality make him virtually inaccessible to the patient who wishes to seek advice on this subject. The subtly rebuffed patient cannot distinguish between the physician's discomfort and the appropriateness of his sexually oriented questions or needs. Often the result is that open discussion is made impossible.

This study was supported in part by Rehabilitation Research and Training Centre Grant No. RT-2, Social and Rehabiliation Services, Department of Health, Education and Welfare, Washington, D.C. 
Another problem arises when the interested physician turns to the medical literature for information about sexual function in spinal cord injury. He finds that it seems to be the interest of only a small and select group of individuals, frequently psychologists or physicians with backgrounds in orthopaedics, neurological sciences, urology and rehabilitation medicine who concentrate in the few hospitals with spinal cord injury services. General hospital staffs do not encounter spinal cord injury often enough to develop and maintain skills necessary for high quality care of paraplegics and quadriplegics (Jackson, I972).

Dr. Herbert S. Talbot, (I969) comments that '. . . of all the problems confronting the spinal cord injured patient there is none from which it has taken longer to dispel the mists of ignorance than the matter of sexual function. The unwillingness of the medical profession to inform itself on the subject has been incomprehensible and inexcusable'. Few would deny that sexuality is one of life's major forces, one which guides and shapes the patient's psycho-social rehabilitation. It may express itself in a variety of forms and in modern society cannot simply be equated with sexual intercourse. In this, as in many other instances, man has transformed a physiological function into a behavioural pattern. Of great importance to the paraplegic and quadriplegic is the awareness that the satisfactions and sense of adequacy derived from one's sexuality may be quite independent of the presence or absence of bodily sensation.

Most of the literature focuses on sexual intercourse. In a study of Ioo cases Zeitlin et al. (1957) concluded that 64 per cent of spinal cord injured males had achieved complete penile erection and 26 per cent. had comsummated successful intercourse. Of those practising intercourse, 5 per cent. experienced orgasm and 3 per cent. ejaculation. In another study of 655 patients with traumatic spinal cord injury, Tsuji et al. (I96I) reported that 54 per cent. of male patients were capable of erection after injury. Erectile ability was recovered in 60 per cent. of the patients within 6 months after injury, and in 80 per cent. within I year after injury. In a study of I 50 patients, Comarr (1970) reports that the overall incidence of psychically stimulated erections was 23 per cent., spontaneously occurring erections 75 per cent. and mechanically stimulated erections $7 \mathrm{I}$ per cent. Of the I 50 patients, $3^{8}$ per cent. did not attempt coitus, $3^{8}$ per cent. did attempt it but 24 per cent. were unsuccessful in their efforts.

It is not surprising that most of the medical literature is concerned with male sexuality since the overwhelming majority of spinal cord injured patients are men. Where the sexuality of spinal cord injured women is the subject of medical writings, it tends to concentrate on the return of menstruation, conception, pregnancy and delivery after injury (Guttmann, 1963; Comarr, I966; Göller \& Paeslack, 1970; Oppenhimer, I971; Robertson, 1972).

The misunderstandings, misinterpretations and myths of sexual function in spinal cord injury continue to influence the medical practice of today. As Herman (1950) points out, many hospital personnel, including nurses, neurosurgeons and neurologists who work with paraplegic patients, have the impression that the paraplegic's sexuality is heightened. This impression is based on the frequent reflex response of the penis to slight stimuli (reflex penile erections), the profusion of provocative pin-up girls often seen at the bedside and the patients' open and casual discussion or jokes about sex. Conversely, the frightened and inhibited sexual expression of other patients has convinced some hospital personnel that loss of sensation of the genital organs causes an absence of sexual excitation. Such 
thinking has helped to propagate the myths of sexual inadequacy thereby compounding the problems of the person physically disabled from spinal cord injury. Correctly identifying such ideas as myths, while helpful, may not be sufficient to help the clinician in his day-by-day management of the injured patient who is preoccupied with the psychological trauma of the loss of normal body functions.

Recently Catherine Breslin (I97I) interviewed a number of spinal cord injured veterans at the Bronx V.A. Hospital. She learned that some mourned their lost sexual abilities more than any other functional loss. For such individuals, the questions of erection, ejaculation and orgasm barely scrape the surface. For them, resumption of sexual activity may become a matter of developing alternative sexual options other than penile-vaginal intercourse. The same study by Breslin indicated that previously the loss of ambulation was the overriding concern of spinal cord injured veterans. However, more recently sexual loss seems to have become increasingly important. For some, regaining sexual performance is more important than regaining the ability to walk.

\section{PHYSIOLOGIC ASPECTS OF SEXUAL FUNCTION IN SPINAL CORD INJURY}

To understand the sexuality of the spinal cord injured person, it is convenient to think of three major aspects of sexuality: psychic, gonadal and neuromuscular. It should be pointed out that the confusion which has existed in evaluating psychic factors has arisen because they have not always been distinguished from awareness of bodily sensation. Loss of somatic sensation is frequent in paraplegia, but in the vast majority of patients, psycho-sexual content remains substantially normal in spite of loss of sensation over primary erogenous zones such as the genitals. As Talbot (1949) points out, 'Allowing for the distractions of illness, discomfort, and fear which are antagonistic to libidinous impulses in neurologically intact individuals; spinal cord injured patients retain the same erotic interest they exhibited before injury'. Hohmann (1972) points out that sexual relationships may be defined in many ways: the orgastic response, for purposes of procreation, bolstering ego and self esteem, and a means of manipulating another person, or, as a means of personality expression blending symbolic and physical feelings of mutual respect, caring and pleasuring.

Penile erection results from stimuli which are either psychogenic or reflexogenic. In the final analysis, psychogenic stimulation eventuates also in reflex function, the difference being that the reflex activation occurs in the brain rather than in the spinal cord. Suitable stimuli are of many types, visual, auditory and olfactory as well as perceptual, recognition and fantasy (Tarabulcy, 1972).

Reflex erection results from visceral and external stimulation. External stimuli, however, are usually tactile and applied to the external genitalia, the frenulum of the penis being the most sensitive area. Noxious stimuli such as freezing with ethyl chloride spray abolishes the reflex erection of patients with upper motor neuron lesions following a spinal cord injury. This procedure is deliberately used during cystoscopy when erections interfere with instrumentation. Visceral stimulation is usually from an unknown origin and causes 'spontaneous' erections. Such unknown stimuli may originate in the pelvic viscera, bladder or rectum of individuals with either intact or damaged spinal cords.

It is frequently observed that reflex erections can be seen in most patients 
with complete upper motor neuron lesions at any level, but with a maximal incidence in patients with cervical lesions. This suggests that the length of the intact and isolated spinal cord below the level of injury is as important for the autonomic reflex function of erection as it is known to be for the somatic reflex spasticity of skeletal muscle. Some patients with complete upper motor neuron lesions may ejaculate. Their perception of this may be a strongly increased general spasticity before and extensor spasticity at the point of ejaculation. This may then be followed by complete flaccidity which may last for several hours. On the other hand, 20 per cent. of patients with lower motor neuron lesions ejaculate (Bors \& Comarr, I960) even though there is complete anaesthesia of the skin of the external genitalia.

The sensation of orgasm may or may not accompany ejaculation. Orgasm can occur in neurologically intact males lacking seminal vesicles, vas deferens or the prostate. It may also occur in spite of denervation of the smooth muscles, just so long as the striated muscles of the pelvic floor and the skin of the genitalia remain innervated. On the other hand, orgasms in a patient with a damaged spinal cord can occur in spite of loss of sensation over the genitalia and denervation of the striated pelvic floor muscles if the smooth muscles of the adnexa remain innervated. Ejaculation may be visible and external, or retrograde into the urinary bladder. Thus, orgasm in one form or another, may be retained as long as either the autonomic innervation of the adnexa or the somatic innervation of the pelvic floor muscles remains intact.

Libido is the desire to copulate and does not depend on the presence of bodily sensation. Animal experimentation in dogs and cats of both sexes confirms this view. It is not uncommon for paraplegics to experience phantom sensations of genital awareness by erotic stimulation of other erogenous zones. This may occur in up to 25 per cent. of cases.

Although the majority of paraplegics and quadriplegics do not experience orgasm or ejaculation, experimental work now in progress suggests that electrical stimulation of the seminal vesicles and vas deferens can produce retrograde ejaculation (Bensman \& Kottke, I966). Sperm can be collected from the bladder in significant counts. This technique can be applied to humans, but as yet recovery of sufficient viable sperm for purposes of artificial insemination has not been reported. The method holds promise, however, since animal breeders have for many years been using electrical stimulation as a method of obtaining sperm (Rowan et al., I962; Guttmann, I97I). (Guttmann (I97I) reported conception from ejaculation obtained from use of intrathecal Prostigmin in man.

\section{THE MINNESOTA PROGRAMME}

Even among hospital staff who are knowledgeable about the physiologic aspects of sexuality after spinal cord injury, the problem remains of how to help the patient deal with the psychological components. The overriding problem is the need to understand more about the wheelchair-bound person's feeling about himself and his sexuality. We need to provide a way to channel those feelings positively.

To accomplish this, we, at the University of Minnesota, experimented with a sex education programme adapted from a training programme for medical students. In 1970 the National Sex and Drug Forum, a division of the (Methodist) Glide 
Foundation, San Francisco, presented a sound and sight programme of sex education for interested students from the University of Minnesota medical school faculty. The programme used speakers and films of explicit sexual activity together with trained professional leaders for small group discussions. It dealt directly. with sexual attitudes by means of demythologising sexual behaviour and desensitising students to hasty or emotional over-reaction to sexual stimuli. At the same time, a resensitisation toward gentle, humanistic and professional understanding of the sexuality of self and others was attempted.

Supplemented with lectures, related reading and examinations, this method of education has now become part of the required curriculum for medical students at the University of Minnesota Medical School (Chilgren, I97I) (Rosenberg). A comprehansive Programme in Human Sexuality has been organised across disciplinary lines to teach, research and provide service in many areas of human sexuality. One of these is sexual function in physical disability.

The medical school model served as the framework for the unique Minnesota programme in human sexuality for paraplegic and quadriplegic men and women. An intensive 2-day programme for both spinal cord injured and able-bodied persons has been developed to deal with sexual attitudes and activities.

A group of eight spinal cord injured adults and their spouses asisted the medical staff in organising the content of the first programme. Personal invitations were sent to paraplegics, quadriplegics and health professionals working with the disabled.

Fifty-five participants, ranging in age from $16-59$, took part in the first workshop. Four were below the age of 20, I4 between the ages of 20-29 and 37 were 30 years of age or more. Paraplegic and quadriplegic participants ranged in age from 16 to 55, and the able-bodied participants from 25-59 years. Each participant was encouraged to bring his spouse or a close friend with whom he could discuss personal and sexual matters. It was believed that the learning would continue after the workshop ended if the individual and someone with whom he would be in close conversational contact attended together.

The first ro hours of the workshop were spent in desensitising the participants to explicit sexual materials so that they could deal with their own sexual feeling more easily during the remainder of the programme. Slides, speakers, panels and films were sequenced in a deliberate manner to stimulate and facilitate the participant to deal first with nudity, then with progressively more explicit and anxiety evoking sexual material. The presentations and films explained or graphically displayed conventional and controversial aspects of human sexuality. The formal content included summaries of some of the pertinent literature recast for ready understanding by people with no medical background. Also included were movies of selected aspects of human sexuality including fantasy, male and female masturbation, male and female homosexuality, heterosexuality, sexual therapy and sexuality of the spinal cord injured person. Pornography as a desensitising medium was utilised in saturation doses midway through the programme. Essential to the process were small group discussions with I2 to I4 persons per group. These were lead by an experienced group leader whose task was to facilitate conversation about feelings in the group.

While the explicit materials and large group discussions were very effective in bringing out each person's reactions and anxieties, it was the purpose of the small groups to put these feelings into perspective. The groups permitted develop- 
ment of a tolerant attitude toward sexual awareness of others in the group and allowed integration of the material, both felt and learned, into the total personality.

Since the small discussion groups represent such a critical aspect of the learning, it is important to review their typical course. And since the programme for the spinal cord injured grew out of the medical student training programme we will first describe the small group discussions in the medical student programme. This will then enable a comparison with the paraplegia groups and an analysis of the differences observed.

The medical student programme usually has four small group sessions spaced throughout the 2 days. Four stages of group development can be characterised to correspond to each of the four meetings. No group follows the pattern completely, each having a unique development depending on its leader and membership variables. However, the correspondence of any group to the outlined dynamic possibilities has been close enough to serve as a 'comfort blanket' for new group leaders coming into the programme.

The first session was devoted to developing comfort and ease within the group. Discussion at this session tends to be in terms of past experience rather than present and follows a somewhat developmental sequence, i.e. talk of childhood behaviour, masturbating experiences, fantasies about sex and parental behaviour.

The second session is often one of self-revelation and discussion on a hereand-now basis. Although again, the group often starts with expressions of disgust and discomfort at the deliberately pornographic, sensual saturation to which it has been exposed, it is much sooner able to admit an interest and excitement during parts of the films. Throughout the session, members achieve a growing recognition of the variety of possible sexual responses.

During the third session, a developing group can expect to find a growing climate of self-acceptance. By the end of this session the group seems to be able to say to each other 'We're okay, we do have hangups, but we also manage them pretty well, and whatever we do is all right'.

The fourth session holds the greatest diversity of topics discussed. Somehow opening up channels of communication about sexual topics seems to encourage communication of other deep seated anxieties and one seems to develop an atmosphere of freedom to discuss. Almost inevitably there is a return to the cognitive approach of the first session.

\section{RESULTS AND DISCUSSION}

Much was learned from this first group of spinal cord injured men and women, the group of hospital health professionals and spouses or friends. Fortyfour per cent. of the group had never been married while 50 per cent. were. Twenty per cent. of the group were paraplegic, 20 per cent. quadriplegic; is 5 per cent. were spouses of spinal cord injured people. The remainder of the group was made up of health professionals or personal friends of the paraplegic and quadriplegic participants.

Forty per cent. of the paraplegics and quadriplegics had completed senior high or vocational school and 45 per cent. had completed college or graduate school. The duration of their spinal cord injuries ranged from less than 2 years to more than I 5 years, with 90 per cent. of the paraplegics and quadriplegics having had their injuries more than 3 years. 
The small group discussions for the spinal cord injured members generally followed the pattern described for the medical student programme, but with interesting differences. There was a curious lack of interest in the topic of masturbation. With medical school groups there was an almost childish glee as they recounted early experiences and memories. The wheelchair group, while mentioning masturbation, frequently dismissed it as a serious topic for themselves. Conversation tended to focus on one person masturbating another, information and theories of masturbation or even the favourite horror stories they had heard about, even though almost all of them had had able-bodied childhoods and presumably equal masturbatory experiences.

The disabled groups quickly came to grips with meaningful discussions. There was less social chit-chat than in the medical student groups and fewer expressions of boredom, criticism of film technique, annoyance, etc. The disabled were ready and able to discuss their sexual concerns much more openly and less defensively than the able-bodied groups. Perhaps the long experience with hospitals made the paraplegic and quadriplegic members more able to discuss openly the intimate physical details of their bodily functions with each other.

Throughout the sessions the particular problems of the wheelchair-bound person were central to the discussion. Of particular concern was the status of his ability to reproduce and his concern for his self-image. These topics were brought into focus early in the programme.

Midway through the programme, after the period of heavy desensitisation, the disabled groups discussed homosexuality as did the medical student groups. However, the discussion began to zero in on the personal injury each had suffered. Oral-genital sex was much more acceptable and the role of fantasy was very strong. The ability to substitute satisfaction of one's partner for personal physical satisfaction and to use the partner's sensory experience to stimulate one's own sexual fantasy became evident.

Toward the end of the programme when resensitisation and human relationships were being stressed, we found a group willingness to share the adjustments each member had made to his disability. Intragroup discussion became particularly relevant at this time, for the groups directly faced the problem of 'wheelchair and walker' relationships. The deep-seated concerns and sensitivities of each toward the other opened. Many bitter stories were told by the wheelers. Much support and respect were accorded them by their partners as well as the ablebodied health professionals in the group. A colleague relationship, rare and fragile, was frequently obtained between what previously might have been patient and therapist. Many spinal cord injured persons complained about the protective, fatherly attitude typically adopted by the attending physician. While this may sustain the physician's ego, it does nothing to help the patient develop his or her new self-image with an altered, but functioning, sense of self-sufficiency.

At the end of the programme, discussions in the disabled groups had testimonials of greater warmth and feeling than did discussions by the able-bodied. There were very concrete recommendations for future use of the programme. Much time was spent discussing the appropriate stage in the rehabilitation process for this programme to be presented. There was unanimous support for incorporating the experience in the training programmes for all workers in the field of spinal cord injury. Many former patients felt that it should be required for anyone wishing to work with the disabled. 
The following brief ranking and comparison of the ten most frequent topics of discussion by the medical school and spinal cord injured groups highlights the above discussion (Fig. I).

FIG. I

\section{TOPICS OF DISCUSSION RANKED BY FREQUENCY}

\section{Medical School Group}

I. Evaluation of the programme and discussions of boredom and saturation.

2. Body touch, massage, body games turnons and turn-offs, sex practices and techniques, body language.

3. Cultural attitude toward sex and society, moralising guilt, child rearing and parental sex roles.

4. Homosexuality-bestiality.

5. Sex related to medical practice.

6. Masturbation.

7. Relationships and feelings in sex (love, trust, jealousy, etc.).

8. Current issues, abortion, death, drugs, problems of sex for disabled, pornography.

9. Imagination, fantasy.

Io. Marriage, extra-marital and premarital sex and divorce.

\section{Spinal Cord Injured Group}

I. Sex for the wheeler, identity, self image, compensations, problems of reproduction.

2. Body touch, turn-ons and turn-offs, body image.

3-4. Evaluations of programme, expectations, communication between wheelers and walkers, relationships and comparisons of problems.

5-6. Personal injury experiences, present or prior life styles, masturbation.

7. Homosexuality.

8. Other sex issues, pornography, bestiality, sadomasochism.

9. Personal sex and marital insight, need for sex education.

IO. Fantasy.

An anonymous questionnaire completed several days prior to the workshop served as a basis for analysis of sexual knowledge, attitudes and behaviours of the participants prior to the 2-day intensive educational experience. Questions were asked about the participant's attitudes, experiences, sexual behaviours and sex counselling while hospitalised for their spinal cord injuries.

When asked if a satisfactory, active sex life is important to the personal happiness of the paraplegic and quadriplegic, the preponderant majority of ablebodied and disabled people agree that it is (Fig. 2).

It is interesting to note, however, that the amount of agreement seemed to be inversely related to the severity of functional loss caused by the spinal cord injury. Although 50 per cent. of the quadriplegic men and women agreed or strongly agreed that a satisfactory and active sex life is important to the personal happiness of the individual, there was similar agreement among 70 per cent. of the paraplegics. Although approximately 70 per cent. of all respondents attested to the 
importance of an active, satisfactory sex life, the paraplegics and quadriplegics engaged in sexual intercourse less often than did the able-bodied workshop participants (Fig. 3).

Forty-five per cent. of paraplegics and quadriplegics had intercourse less than once a month, but only 12 per cent. of able-bodied people, other than the paraplegics' and quadriplegics' spouses, had a similarly low frequency of sexual intercourse. On the other hand, 70 per cent. of the able-bodied people, other than the spouses of the spinal cord injured, engaged in sexual intercourse more than once a week, whereas only 40 per cent. of the paraplegics and quadriplegics did so.

FIG. 2

It is very important to the personal happiness of the paraplegic and quadriplegic to have a satisfactory and active sex life

Male and female paras

Male and female quads

Strongly
agree
$(\%$

Able-bodied spouses of paras and quads

Able-bodied males

Able-bodied females

$\begin{array}{ccccc}\begin{array}{c}\text { Agree } \\ (\%)\end{array} & \begin{array}{c}\text { Neutral } \\ (\%)\end{array} & \begin{array}{c}\text { Disagree } \\ (\%)\end{array} & \begin{array}{c}\text { Strongly } \\ \text { disagree } \\ (\%)\end{array} & \begin{array}{c}\text { No } \\ \text { answer } \\ (\%)\end{array} \\ 40 & 0 & 20 & 0 & 10 \\ 30 & 10 & 20 & 10 & 10 \\ 37 & 13 & 13 & 0 & - \\ 55 & 9 & 9 & 0 & - \\ 55 & 5 & 5 & 0 & 9\end{array}$

FIG. 3

SEXUAL INTERCOURSE

How often during past 6 months have you had sexual intercourse?

$\begin{array}{lcc} & \begin{array}{c}\text { Paras and quads } \\ (\%)\end{array} & \begin{array}{c}\text { Abled-bodied other than } \\ \text { spouses of paras and quads } \\ (\%)\end{array} \\ \text { Less than once/month } & 45 & \text { I2 } \\ \text { Once/week or more } & 40 & 70 \\ \text { Not answered } & 5 & \text { I8 }\end{array}$

It is interesting to speculate whether or not the reason for the lowered frequency is related to satisfaction. When asked if they had enjoyed intercourse during the last 6 months, 70 per cent. of the paraplegics and quadriplegics reported that they did, most or all of the time. This figure compares well with the able-bodied people, discounting the spouses of the paraplegics and quadriplegics, 75 per cent. of whom agreed that they enjoyed intercourse most or all of the time (Fig. 4).

What are some of the possible explanations for the lower frequency of sexual contact? The relative proportions of married and single respondents was not sufficient to explain the difference. When given a list of alternatives from which to choose, most spinal cord injured and able-bodied workshop participants agreed that the most serious sexual problems of the spinal cord injured person were unavailability of sexual partners (from whatever cause) and lack of knowledge on the part of the injured person about prospects for a satisfactory sex life. The unavailability of the sexual partner may be linked to the relative physical immobility of the spinal cord injured person whose freedom to circulate in society is hampered 
by his physical disability and the architectural barriers encountered. Other possible explanations include the general reluctance of able-bodied people to associate closely with the obviously physically disabled (Jewson, I963) thus further reducing the contact frequency of the spinal cord injured person with a potentially available able-bodied sexual partner.

Many health professionals working in hospital and rehabilitation settings are aware of the general unwillingness of the hospital staff to discuss the sexuality of the spinal cord injured patients. This may contribute to the propagation of the myth of sexual inadequacy. Sixty per cent. of the paraplegics and quadriplegics interviewed indicated that the amount of attention paid to their sexual condition was almost none (Fig. 5).

FIG. 4

Did you enjoy intercourse during past 6 months?

$\begin{array}{lcc} & \begin{array}{c}\text { Paras and quads } \\ (\%)\end{array} & \begin{array}{c}\text { Able-bodied other than } \\ \text { spouses of paras and quads } \\ (\%)\end{array} \\ \text { Never or rarely } & \text { I0 } & 0 \\ \text { Rarely or some of the time } & - & 0 \\ \text { Most or all of the time } & 70 & 75 \\ \text { Not answered } & 20 & 25\end{array}$

FIG. 5

When I was first injured and in the hospital I believe that the attention paid to my sexual condition was:

$\begin{array}{lcc} & \text { Paras (\%) Quads (\%) } \\ \text { Almost none } & 60 & 60 \\ \text { Poor } & \text { I0 } & \text { I0 } \\ \text { Fair } & \text { IO } & \text { I0 } \\ \text { Good } & \text { IO } & \text { IO } \\ \text { Excellent } & \text { IO } & -\end{array}$

FIG. 6

Of the information I did receive, most of it came from:

$\begin{array}{lll}\text { Doctor } & 50 & 30 \\ \text { Psychiatrist } & \text { Io } & -\ldots . \\ \text { Aide-Orderly } & \text { IO } & 30 \\ \text { Other } & \text { IO } & 30 \\ \text { No answer } & 20 & 40\end{array}$

Only 20 per cent. of the disabled indicated that the attention paid to their sexual condition was either good or excellent. The respondents also reported that the hospital staff took little initiative in discussing the patients' sexual lives and prospects. Ninety per cent. of the paraplegics and 80 per cent. of the quadriplegics indicated that never or seldom did the hospital staff take the initiative to discuss the factual implications of the spinal cord injury. When the information was 
extended to the patient, it was most often given by the physician (fig. 6), but other people including psychiatrists, aides, orderlies and other unidentified people also contributed. Nurses were infrequently credited with offering information and hospital clergy were conspicuously absent from the list.

Since the physical disability associated with spinal cord injury may make penile-vaginal intercourse impossible, difficult, awkward or time consuming, many paraplegics and quadriplegics have found that oral-genital sexual activity is an important part of their sexual behaviour. When this mixed group of men and women, ranging from teenagers to 59 years of age, were asked if they found the idea of oral-genital sexual activity attractive, the overwhelming majority of all respondents indicated that they did.

FIG. 7

Do you find the idea of oral-genital sexual activity attractive or unattractive? $\%$ who find it attractive

$\begin{array}{lr}\text { Paraplegic men and women } & 60 \\ \text { Quadriplegic men and women } & 90 \\ \text { Spouses of paras and quads } & 88 \\ \text { Able-bodied males } & \text { IOO } \\ \text { Able-bodied females } & 86\end{array}$

FIG. 8

Have you tried oral-genital sexual activity? $\%$ having tried it

$\begin{array}{lr}\text { Paraplegic men and women } & 70 \\ \text { Quadriplegic men and women } & 70 \\ \text { Spouses of paras and quads } & \text { rOO } \\ \text { Able-bodied males } & 9 \mathrm{I} \\ \text { Able-bodied females } & 95\end{array}$

FIG. 9

If you did try oral-genital sexual activity, did you enjoy it?

$\begin{array}{lr}\text { Paraplegic men and women } & 86 \\ \text { Quadriplegic men and women } & \text { 100 } \\ \text { Spouses of paras and quads } & \text { 100 } \\ \text { Able-bodied males } & \text { 100 } \\ \text { Able-bodied females } & 95\end{array}$

Sixty per cent. of paraplegic men and women stated that the idea of oralgenital sex was attractive to them. Ninety per cent. of quadriplegic men and women agreed. This compares to an 88 per cent. agreement by the spouses of the paraplegics and quadriplegics, most of whom were women. Eighty-six per cent. of the other able-bodied women in attendance also agreed to such attractiveness, as did Ioo per cent. of the able-bodied males responding to the question.

Not only is the idea of oral-genital sexual activity attractive, but 70 per cent. of the paraplegic and quadriplegic men and women have tried it.

When only the married spinal cord injured were asked if they had tried oralgenital sex, Ioo per cent. of them and their spouses stated that they had. Among those who tried oral-genital sex, 86 per cent. of the paraplegics said that they enjoyed it, and 95 to 100 per cent. of the quadriplegic men, the spouses of the I $/ 2-K$ 
paraplegics and quadriplegics and the able-bodied males and females at the workshop agreed (fig. 9). This seems to attest to the importance of oral-genital sex as an option for this group.

Since this method of sex education and therapy for physically disabled people was new, an immediate post-workshop evaluation was completed by everyone in attendance. We felt that an important measure of its value could be found in the answer to a simple question, 'Are you glad you attended the workshop on sexual function in spinal cord injury ?' (fig. Io). It should be remembered however, that the participants were personally invited to attend the workshop and therefore would be expected to react favourably to the educational experience.

A second simple but important measure of the workshop is found in the answer to the question 'Has the workshop in sexual function in spinal cord injury been helpful or harmful to you ?' (fig. I I).

FIG. IO

Are you glad you attended the workshop on sexual function in spinal cord injury?

Glad or very glad
Neutral
Sorry or very sorry

$$
\begin{array}{r}
\text { I00\% } \\
0 \% \\
0 \%
\end{array}
$$

FIG. II

Has the workshop in sexual function in spinal cord injury been helpful or harmful to you?

$$
\begin{array}{lr}
\text { Helpful } & 98 \% \\
\text { No effect } & 2 \% \\
\text { Harmful } & 0 \%
\end{array}
$$

FIG. I2

Should a deliberate programme dealing with human sexuality be offered on a voluntary basis to all spinal cord injured adults?

$$
\begin{aligned}
& \text { Yes } \\
& \text { Not answered } \\
& \quad 2 \%
\end{aligned}
$$

Ninety-eight per cent. of the able-bodied and disabled respondents indicated that the 2-day experience had been helpful to them and only 2 per cent. indicated that it had no effect. No one indicated that it had been a harmful experience.

On the basis of these favourable responses, the participants were asked if a deliberate programme dealing with human sexuality should be offered on a voluntary basis for all spinal cord injured adults. Ninety-eight per cent. of the participants agreed that it should (fig. 12).

The question of when such a deliberate programme should be offered was also asked. Able-bodied and disabled agreed in relatively the same proportions that it should be offered during the first hospitalisation but certainly within the first 6 months after injury (fig. I3).

This form of sex education and therapy may be an efficient vehicle to reach large numbers of people in a relatively brief time. 'What we must do', says Dr. Herbert S. Talbot (I949) 'if we are to fairly consider sexual function in these patients is to first consider the place of sexuality in modern life, generally speaking. 
Only a very small portion of our libidinous energy and capacity is devoted to procreation. A greater part is expanded in the search for gratification along the whole broad spectrum implied by that word'.

FIG. I3

When should a deliberate programme in sexual function be offered to spinal cord injured adults?

$\begin{array}{lcccc} & \begin{array}{c}\text { During ist } \\ \text { hospitalisation } \\ (\%)\end{array} & \begin{array}{c}6 \text { months } \\ \text { after injury } \\ (\%)\end{array} & \begin{array}{c}\text { I year } \\ \text { after injury } \\ (\%)\end{array} & \begin{array}{c}\text { Not at all } \\ (\%)\end{array} \\ \text { Male paraplegics } & 50 & 25 & 25 & \circ \\ \text { Female paraplegics } & 40 & 40 & 20 & 0 \\ \text { Male able-bodied } & 53 & 31 & 8 & 0 \\ \text { Female able-bodied } & 36 & 45 & 9 & 0\end{array}$

(Some able-bodied did not answer this question)

If any myths about sexuality and the spinal cord injured person have been dispelled to the satisfaction of the workshop participants, it is the myth that sex cannot or should not be discussed frankly with the physically disabled person. Workshop participants demonstrated that they not only were interested in discussing their own sexuality in relationship to that of the able-bodied world, but in many respects seemed capable of dealing with anxiety producing material in a more direct and tolerant manner than many of the able-bodied people who participated with them.

While the small group discussions provided a unique experience for all members attending the sex education workshops, they created a particularly poignant atmosphere for the physically disabled people. They recognised in a behavioural as well as a purely cognitive way, that spinal cord injured people are still sexual beings with feelings, anxieties and opinions. Respect and sanction were given to the unique types of sexual adjustments the disabled had attained. Most of all, the wheelers and walkers had an opportunity to confront each other on a peer level in a highly emotional setting.

A comparison of gains between able-bodied and disabled people is not justified from this limited experience. Nevertheless, it appeared to the observers that able-bodied health professionals attending the workshop emerged from the sessions educated equally, if not more, than their former patients.

\section{SUMMARY}

A new programme in sex education and counselling for spinal cord injured adults and health care professionals has been described. The format of the 2-day desensitising-resensitising programme included exposure to a programmed assortment of explicit slides and films of sexual activity. Periodic small group discussions led by trained group leaders constituted the most important part. The results suggest that continued sexual interest, activity and satisfaction can be anticipated for many paraplegics and quadriplegics. An accepting, experimental attitude toward sexual activity promotes satisfaction with an interested and caring partner. However, many health professionals deliver inadequate sexual counselling to 
patients with spinal cord injury. This may add to the sum of the disabilities carried by the paraplegic and quadriplegic adult.

\section{RÉSUMÉ}

Un nouveau programme d'éducation sexuelle pour les traumatisés médullaires adultes avec des conseillers professionnels est décrit.

Les résultats suggèrent que l'intérêt sexuel, l'activité et la satisfaction peuvent être anticipés pour beaucoup de paraplégiques et de tétraplégiques. Il est noté que beaucoup de conseillers professionnels donnent des conseils sexuels inadaptés aux malades avec traumatisme médullaire, ce qui peut encore intensifier leur handicap.

\section{ZUSAMMENFASSUNG}

Ein neues Programm in sexueller Belehrung in Querschnittslähmungen wird beschrieben mit Einschluss von Demonstrationen von Filmen und Diapositiven. Periodische Gruppendiskussionen unter Leitung von geschultem Personal werden abgehalten. Die Ergebnisse äeigen en dauerndes Interesse, Aktivstät und Satisfaktion bei vielen Para- und Tetraplegikern.

Acknowledgements. The authors wish to express their gratitude to Ms. Maureen Stevens for her editorial and technical assistance in the preparation of this manuscript.

\section{REFERENCES}

Bensman, A. and Kottke, F. J. (1966). Archs phys. Med. Rehabil. 47, 436-442.

Bors, E. \& Comarr, A. E. (I960). Urol. Surv. 10, I91-222.

BRESLIN, C. (I97I). 'In a Ward at the Bronx V.A.: Talking about the Unspeakable', New York, 43-52.

Chilgren, R. A. (I97I). 'Education, Research, and Therapy to Improve Sexual Help', Interdisciplinary Program in Human Sexuality, Office of the dean, Medical School, Univ. of Minn., 9-I 6.

Comarr, A. E. (1966). Med. Servs. F. Can. 22, 65I-66I.

CoMARR, A. E. (I970). Urol. int. 25, I34-I68.

Göller, H. \& PAeslack, V. (I970). Paraplegia, 8, I6I-I66.

Guttmann, L. (1963). Proc. Roy. Soc. Med. 56, 383-387.

Guttmann, L. (I97I). Paraplegia, 9, 38-5I.

Herman, M. (1950). Archs. Neurol. Psychiat. Chicago, 64, 42-56.

Hohmann, G. W. (1972). Rehabil. Psychol. 19, 50-58.

JACKSON, R. W. (1972). Paraplegia, 10, 50-55.

Jewson, R. H. (I963). F. Home Econ. 55, 620-624.

KuHN, R. A. (1950). Brain, 73, I-5I.

Munro, D., Horne, H. W., Jr. \& Paull, Capt. D. P. (1948). New Engl. F. Med. 239, 903-9I I.

OPPENHIMER, W. M. (I97I). Amer. F. Obstet. Gynec. II 0, 784-786.

Proceedings of the Conference on Medical and Consumers Problems of Paraplegics and Quadriplegics, National Paraplegic Foundation, June 24, I971.

Robertson, D. N. S. (1972). Paraplegia, 10, 209-212.

Rosenberg, P. \& Chilgren, R. A. 'Sex Education Discussion Groups in a Medical Setting', accepted for publication, Int. F. Grp. Psychother.

Rowan, R. L., Howley, T. F. \& Nova, H. R. (I962). F. Urol. 87, 726-729.

TALBOT, H. S. (I949). F. Urol. 6r, 265-270.

TALBOT, H. S. (1955). F. Urol. 73, 91-IOO.

TAlbot, H. S. (1969). Proceedings of Seventeenth Veteran's Administration Spinal Cord Injury Conference, Veteran's Administration Hospital, Bronx, New York, 222-223.

Tarabulcy, E. (1972). Paraplegia, 10, 20I-208.

Tsuji, I., Nakajima, F., Morimoto, J. \& Nounaka, Y. (196I). Urol. int. 12, 270-280.

Zeitlin, A. B., CotTrell, T. L., Lloyd, F. A. (1957). Fert. Steril. 8, 337-344. 